\title{
A genomic perspective on a new bacterial genus and species from the Alcaligenaceae family, Basilea psittacipulmonis
}

Katrine $L$ Whiteson ${ }^{1,5^{*}}$, David Hernandez ${ }^{1}$, Vladimir Lazarevic ${ }^{1}$, Nadia Gaia ${ }^{1}$, Laurent Farinelli ${ }^{2}$, Patrice François ${ }^{1}$, Paola Pilo ${ }^{3}$, Joachim Frey ${ }^{3}$ and Jacques Schrenzel ${ }^{1,4}$

\begin{abstract}
Background: A novel Gram-negative, non-haemolytic, non-motile, rod-shaped bacterium was discovered in the lungs of a dead parakeet (Melopsittacus undulatus) that was kept in captivity in a petshop in Basel, Switzerland. The organism is described with a chemotaxonomic profile and the nearly complete genome sequence obtained through the assembly of short sequence reads.

Results: Genome sequence analysis and characterization of respiratory quinones, fatty acids, polar lipids, and biochemical phenotype is presented here. Comparison of gene sequences revealed that the most similar species is Pelistega europaea, with BLAST identities of only $93 \%$ to the $16 \mathrm{~S} \mathrm{rDNA}$ gene, $76 \%$ identity to the rpoB gene, and a similar GC content ( 43\%) as the organism isolated from the parakeet, DSM 24701 (40\%). The closest full genome sequences are those of Bordetella spp. and Taylorella spp. High-throughput sequencing reads from the Illumina-Solexa platform were assembled with the Edena de novo assembler to form 195 contigs comprising the $2 \mathrm{Mb}$ genome. Genome annotation with RAST, construction of phylogenetic trees with the 16S rDNA (rrs) gene sequence and the rpoB gene, and phylogenetic placement using other highly conserved marker genes with ML Tree all suggest that the bacterial species belongs to the Alcaligenaceae family. Analysis of samples from cages with healthy parakeets suggested that the newly discovered bacterial species is not widespread in parakeet living quarters.

Conclusions: Classification of this organism in the current taxonomy system requires the formation of a new genus and species. We designate the new genus Basilea and the new species psittacipulmonis. The type strain of Basilea psittacipulmonis is DSM 24701 (= CIP 110308 T, 16S rDNA gene sequence Genbank accession number JX412111 and Gl 406042063).
\end{abstract}

Keywords: Bacteria, Parakeet, High-throughput sequencing, Genome, Phylogenetic profile

\section{Background}

The study of parakeet respiratory infection has had important implications for biomedical research since December of 1929, when psittacosis caused by Chlamydophila psittaci created a health scare which eventually led to the formation of the National Institutes of Health [1]. Here we describe a novel bacterium from the family

\footnotetext{
* Correspondence: katrinewhiteson@gmail.com

${ }^{1}$ Genomic Research Laboratory, Department of Internal Medicine, Service of Infectious Diseases, Geneva University Hospitals, Gabrielle-Perret-Gentil 4, CH-1211 Geneva 14, Switzerland

${ }^{5}$ Current address: Department of Biology, San Diego State University, San Diego, CA, USA

Full list of author information is available at the end of the article
}

Alcaligenaceae that was discovered in the lungs of a dead parakeet (Melopsittacus undulatus) from a petshop in Basel, Switzerland. The bacterial family Alcaligenaceae includes genera that have been isolated from humans, animals and the environment. They are Gram-negative rods or coccobacilli that possess oxidase and catalase, growing well on complex media under aerobic or microaerobic conditions.

There are nearly 25000 prokaryote genome projects registered in the NCBI database as of early 2014 [2], many of them human-associated. Pathogens of animals that are not important for agriculture or zoonotic transmission of disease are poorly studied. Filling out the tree of life is 
important for improving genome sequence annotation and creating good phylogenetic landmarks to analyze metagenomic data $[3,4]$.

The genome of a bacterium isolated from the lungs of a parakeet (Melopsittacus undulatus) in captivity was sequenced using Illumina sequencing. Here we describe the success and limitation of a comparative genomics approach to studying this newly discovered bacterium. This bacterium is most closely related to Pelistega europaea according to a Ribosome Database Project (RDP) classifier assessment of the similarity of their $16 \mathrm{~S}$ rDNA ( $r r s$ ) gene $[5,6]$, a stable and frequently used phylogenetic marker [7]. The closest fully sequenced relatives, from genus Taylorella and genus Bordetella [8-11], share a great number of putative genes and functions, but are too distant to make specific analyses through simple sequence comparisons.

\section{Methods}

\section{Bacterial isolation, phenotypic and biochemical} characterization

The carcass of a suddenly dead parakeet (M. undulatus) from a petshop without previous presentation of clinical signs was brought to the Institute of Animal Pathology, University of Bern, Switzerland for post mortem examination and histological analysis.

Lung and liver samples from the deceased parakeet were cultured on tryptone soy agar with $5 \%$ sheep blood (Oxoid, Basel, Switzerland) at $37^{\circ} \mathrm{C}$ in an atmosphere of air with $5 \% \mathrm{CO}_{2}$ for 48 hours. Phenotypic and biochemical characterization were performed with a VITEK2 instrument (bioMérieux, Geneva, Switzerland) and the API ZYM, API NH and API 20 NE (bioMérieux) according to the manufacturer's instructions. Analysis of respiratory quinones, polar lipids and fatty acids were carried out by the Identification Service of the DSMZ and DR. BJ Tindall, DSMZ, Braunschweig, Germany. Plates were stained with $5 \%$ molybdophosphoric acid to show all lipids.

\section{Submission to international culture collections}

The strain JF4266 was submitted to the Deutsche Sammlung von Mikroorganismen und Zellkulturen (DSMZ, deposited under the name Alcaligenaceae bacterium DSM 24701) and the Institute Pasteur (number CIP 110308 T) with the name $B$. psittacipulmonis. Both repositories have made the strain publicly available under the name B. psittacipulmonis in addition to the strain number assigned by each repository, in accordance with the Rules of Bacteriological Code (1990 revision) as revised by the International Committee on Systematics of Prokaryotes (ICSP) at the plenary sessions in Sydney and Paris [12].

\section{PCR conditions}

The material from the bottom of three cages (with live parakeets) and cage water were obtained from three petshops in Switzerland and France. Cage water was concentrated 50 -fold in a vacuum concentrator. The cage samples were mixed with the lysis buffer [final concentration Tris $10 \mathrm{mM}$, EDTA $1 \mathrm{mM}(\mathrm{pH} \mathrm{8)}$ ), Tween 0.5\%, proteinase K (Fermentas, Burlington, Canada) $200 \mu \mathrm{g} / \mathrm{ml}$ ] and incubated for 2.5 hours at $55^{\circ} \mathrm{C}$ [13]. Proteinase $\mathrm{K}$ was inactivated by a $10 \mathrm{~min}$ incubation at $95^{\circ} \mathrm{C}$ and the samples were frozen at $-20^{\circ} \mathrm{C}$. The PCR contained $6 \mu \mathrm{l}$ of lysate and $0.5 \mu \mathrm{M}$ of both forward and reverse primers in $50 \mu$ of PrimeStar HS Premix (Takara, Otsu, Shiga, Japan). The PCR mix was amplified for 36 cycles (for three putative protein coding regions) or 30 cycles (for the $16 \mathrm{~S}$ rDNA gene) of $98^{\circ} \mathrm{C}$ for 10 seconds, $56^{\circ} \mathrm{C}$ for 15 seconds, and $72^{\circ} \mathrm{C}$ for $1 \mathrm{~min}$. One $\mu \mathrm{l}$ of the amplified reaction mix was run on the Agilent Bioanalyzer using a DNA1000 lab chip to determine if the product was generated. The Per-1 F/R, Per-2 F/R and Per-3 F/R primer pairs amplify 730, 522 and 533 bp regions of the DSM 24701 genomic DNA. The primers were designed to amplify RAST predicted genes of unknown function that are unique to the parakeet genome (there are no Blast hits to the $\mathrm{nr} / \mathrm{nt}$ database). Primer pair Per-11 F/R specifically amplifies a unique298 bp region of the DSM $2470116 \mathrm{~S}$ rDNA, from position 202 to 499. Primer sequences were as follows: Per-1 F 5' TCTGGGTGATTTTGGAGAGG 3', Per-1R 5' ATTCTCGCGTTCTTGCTGTT 3', Per-2 F 5' TTCGTATCTGGCAGAGgCTT 3', Per-2R 5' AACA ATTGGGTTCCCACAAA 3', Per-3 F 5' AGATGATG GAGCAAGCTCGT 3', Per-3R 5' CAATTGGTCTACC GTTGCCT 3', Per-11 F 5' AAAGCAGGGGACCGCA AGGC 3', Per-11R 5' TCAGGTACCGTCATCACTCA ATGGT 3'.

Controls to ensure that the parakeet cage samples did not inhibit PCR reactions were performed in two ways: 1) The parakeet cage material and water lysate were spiked with genomic DNA from DSM 24701, in which case all 3 pairs of DSM 24701 specific primers successfully amplified the expected product. 2) A PCR targeting the first three variable regions of the $16 \mathrm{~S}$ rDNA gene (V123) was also performed on the parakeet cage samples using broad range bacterial $16 \mathrm{~S}$ primers (8 F 5 GAGTTTGATCMTGGCTCAG 3 and 534R 5 CCGCGRCTGCT GGCAC 3). These primers amplified the expected segment of the bacterial $16 \mathrm{~S}$ rDNA gene from all three parakeet cage material and water samples, suggesting that there are bacteria in the sample, as we would expect, but not DSM 24701.

\section{Sequencing}

Genomic DNA was prepared using the procedure in Hernandez et al. [14] using the DNEasy kit (Qiagen, 
Venlo, Netherlands) and sequenced with the Solexa Illumina Genome Analyzer. The 454 sequencing was conducted by Microsynth in Balgach, Switzerland. Optical mapping was carried out by digestion of genomic DNA by NheI with OpGen in Madison, Wisconsin, USA.

\section{Assembly and annotation}

The paired Illumina reads were assembled with the Edena assembler [14]. The assembly of 454 sequencing data was performed with the dedicated GS De Novo Assembler available from Roche (Roche Applied Science, Indianapolis, IN, USA). The final 195 contigs were submitted to the RAST server (Chicago, IL, USA) for annotation [15].

\section{Phylogenetic analysis}

A 1535 bp segment of the $16 \mathrm{~S}$ rDNA gene, found on contig 42 of the draft genome (Genbank accession number JX412111 and GI 406042063) was analyzed with the RDP Classifier [5]. Neighbor joining, maximum-parsimony and maximum-likelihood phylogenetic trees based on $16 \mathrm{~S}$ rDNA sequence were constructed with MEGA 5 [16]. Similarly, a Neighbor Joining tree was constructed with the $r p o B$ gene sequence from the draft genome, Pelistega europaea, and several related taxa. BLASTn was used to exhaustively search all $16 \mathrm{~S}$ rDNA gene sequences available in the NCBI database (Table 1). The dinucleotide usage of the genomes was converted to a Bray-Curtis distance matrix and clustered using multidimensional scaling in Primer [17]. Clustered regularly interspaced Short Palindromic Repeats (CRISPR) detection was conducted with Crisprfinder [18].

\section{Phylogenetic profile}

An array was constructed containing rows of putative genes and columns of fully sequenced bacterial genomes, following the strategy of Wu and Eisen [19]. The absence and presence of a gene in the species is indicated by 0 or 1 , as determined by BLASTp of the predicted genes from DSM 24701 against the SEED database of proteins from fully sequenced genomes with an E-value cut-off of 10E-05. Clusters were made using CLUSTER 3.0 with a complete linkage hierarchical analysis and weighting of the species in an attempt to remove phylogenetic bias, and visualized with JavaTreeview (both available at http:// rana.lbl.gov/EisenSoftware.htm).

\section{Duplication analysis}

BLASTp of the predicted protein sequences from DSM 24701 was performed against a database of the same set of sequences, to find duplicates inside the genome (paralogs). Reciprocal hits and self-hits were excluded, and BLAST results with an E-value cut-off of 10E-05, >150aa long, and $>30 \%$ sequence identity were counted as duplicates, largely following the strategy of Gevers et al. [20]. We excluded all 57 sequences $<150$ aa long in order to avoid overestimating the duplication rate by only including short sequences that do not have a paralog.

\section{Results and discussion}

\section{Bacterium identification}

At necropsy, the post mortem examination of the parakeet revealed that the liver had a marbled surface and the spleen was swollen. No other macroscopic lesions were observed. The histology revealed several abnormalities. The lungs had diffused alveolar edemas and congestion. The heart had multifocal epicardial and myocardial edemas. Spleen and liver had diffuse sinusoidal congestion and multifocal accumulation of histiocytes. Bacterial culture of the lung and liver revealed the presence of small Gram-negative, non-haemolytic, non-motile rods in the lung. Visible colonies of the bacterial strain (initially labeled JF4266 in the lab, and referred to as DSM 24701 in this paper) appeared after 2-day incubation at $37^{\circ} \mathrm{C}$ on blood agar plates in a $5 \% \mathrm{CO}_{2}$-enriched atmosphere. The bacterium did not grow in LB broth or enriched Mycoplasma broth medium (Axcell Biotechnologies, St. Genis l'Argentière, France) at $37^{\circ} \mathrm{C}$ with and without $5 \% \mathrm{CO}_{2}$. A

Table 1 Top BLASTn hits for DSM 24701 16S rDNA gene sequence

\begin{tabular}{|c|c|c|c|c|c|c|}
\hline & Species & Accession & Score & Query coverage & E value & Max identity \\
\hline 1 & Advenella kashmirensis WT001 & CP003555.1 & 2265 & $100 \%$ & 0 & $93 \%$ \\
\hline 2 & Bordetella sp. p23 (2011) & HQ652588.1 & 2255 & $99 \%$ & 0 & $93 \%$ \\
\hline 3 & Uncultured compost bacterium clone ASC718 & JQ775330.1 & 2244 & $99 \%$ & 0 & $93 \%$ \\
\hline 4 & Taylorella equigenitalis $14 / 56$ & HE681423.1 & 2237 & $100 \%$ & 0 & $93 \%$ \\
\hline 5 & Taylorella equigenitalis ATCC 35865 & CP003264.1 & 2237 & $100 \%$ & 0 & $93 \%$ \\
\hline 6 & Taylorella equigenitalis MCE9 & CP002456.1 & 2237 & $100 \%$ & 0 & $93 \%$ \\
\hline 7 & Bordetella sp. d16 & HQ652589.1 & 2235 & $98 \%$ & 0 & $93 \%$ \\
\hline 8 & Achromobacter sp. CH1 & HQ619222.1 & 2231 & $99 \%$ & 0 & $93 \%$ \\
\hline 9 & Achromobacter sp. MT-E3 & EU727196.1 & 2231 & $99 \%$ & 0 & $93 \%$ \\
\hline
\end{tabular}


detailed growth condition profile in comparison with P. europaea, T. equigenitalis and T. asinigenitalis is included in Additional file 1: Table S1. It shows that DSM 24701 and $P$. europaea grow in aerobic or capnophilic conditions at $30^{\circ} \mathrm{C}$ and $42^{\circ} \mathrm{C}$. DSM 24701 interestingly does not grow at $37^{\circ} \mathrm{C}$ in aerobic conditions, but only in capnophilic conditions. The cytochrome oxidase and catalase spot tests were positive while indole was negative. Standard phenotypic analysis could not identify the isolate (Additional file 1: Table S1). The enzyme profile can differentiate DSM 24701 from the type strains of $P$. europaea, T. equigenitalis and T. asinigenitalis (Table 2). The major respiratory quinone of the strain DSM 24701 is Q8 and the major polar lipids are phosphatidylethanolamine, phosphatidylglycerol, two unknown phosphoaminolipids, two unknown phospholipids and two unknown aminolipids. The proportion of several cellular fatty acids from DSM 24701 is reported in Table 3.

\section{Description of Basilea gen. nov.}

Basilea (Ba.si.le'a L. fem. N. referring to the Swiss town Basel, where the type strain was isolated)

Cells are small, Gram-negative, non-motile rods. Oxidasepositive and grows in aerobic or capnophillic conditions. Visible colonies appear after 2 days growth on blood agar plates at $30-42^{\circ} \mathrm{C}$ with $5 \% \mathrm{CO}_{2}$. The major respiratory quinone is Q8 and the major polar lipids are phosphatidylethanolamine, phosphatidylglycerol, two unknown phosphoaminolipids, two unknown phospholipids and two unknown aminolipids. The major fatty acids were $C_{16: 0}$
Table 3 Cellular fatty acid composition of DSM 24701

\begin{tabular}{ll}
\hline Fatty acid composition & DSM 24701 \\
\hline $10: 0$ & - \\
12:0 & TR \\
14:0 & 6.92 \\
14:1 w5C, 14:1 w5t or both & - \\
15:0 & 2.30 \\
15:1 w8c & - \\
16:0 & 35.31 \\
16:0(3-OH) & 1.3 \\
16:1 w5C & TR \\
17:1 w6C & 1.23 \\
18:0 & 1.09 \\
18:1 w5C & TR \\
18:1 w7c & 38 \\
19:0 10-methyl & - \\
20:1 w9t & - \\
Summed feature 1 & TR \\
Summed feature 2 & 9.47 \\
Summed feature 3 & 1.07 \\
Summed feature 5 & TR \\
\hline
\end{tabular}

TR, trace amount $(<1 \%) ;-$, not detected.

Summed feature 1, 15:1 isoH, 15:1 isol, 13:0 3-OH, or any combination.

Summed feature 2, 12:0 ALDE, 14:0 3-OH, 16:1 iso I, or any combination.

Summed feature $3,16: 1 \mathrm{w} 7 \mathrm{c}$ and/or 15 iso 2-OH.

Summed feature 5, 18:2 w6,9c and/or 18:0 ANTE.

Table 2 Differential taxonomic characteristics between DSM 24701, T. equigenitalis (DSM 10668 T), T. asinigenitalis (CIP 79.7 T) and P. europaea (LMG 10982 T)

\begin{tabular}{|c|c|c|c|c|}
\hline Enzyme & P. europaea LMG 10982 T & T. asinigenitalis CIP $79.7 \mathrm{~T}$ & T. equigenitalis DSM $10668 \mathrm{~T}$ & DSM 24701 \\
\hline \multicolumn{5}{|l|}{ API ZYM results ${ }^{a}$} \\
\hline Alcaline phosphatase & 1 & 5 & 5 & - \\
\hline Esterase & 2 & 1 & 1 & 4 \\
\hline Esterase lipase & 1 & - & - & 2 \\
\hline Lipase & 2 & - & - & - \\
\hline Leucine arylamidase & 5 & 5 & 5 & 5 \\
\hline Valine arylamidase & 3 & 2 & 1 & 1 \\
\hline Cystin arylamidase & - & 1 & 1 & - \\
\hline Acid phosphatase & 2 & 3 & 4 & 1 \\
\hline Naphtol-AS-BI-phosphohydrolase & 1 & 2 & 4 & 3 \\
\hline \multicolumn{5}{|l|}{ API NH results ${ }^{b}$} \\
\hline Penicillinase & - & + & - & - \\
\hline Ornithine decarboxylase & - & - & - & W \\
\hline ү-glutamyl transferase & - & + & + & + \\
\hline
\end{tabular}

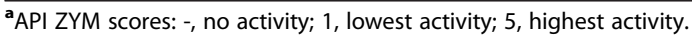

The four strains gave no reaction for indol, trypsin, chymotrypsin, $a$-galactosidase, $\beta$-galactosidase, $\beta$-glucuronidase, $a$-glucosidase, $\beta$-glucosidase, $N$-acetyl- $\beta$ glucosaminidase, a-mannosidase and a-fucosidase, urease and prolin arylamidase.

${ }^{\text {b }}$ API NH results: -, negative; W, weakly positive; + , positive. 
and $\mathrm{C}_{18: 1} \omega 7 c ; \mathrm{C}_{12: 0}$ was only detected in trace amounts. The type species is Basilea psittacipulmonis. The DNA $\mathrm{G}+\mathrm{C}$ content of the type strain of this type species is $40 \%$.

\section{Description of psittacipulmonis sp. nov.}

B. psittacipulmonis (psitt.a.ci.pul.mon'is named because the type and only known strain was isolated from the lung of a parakeet). The description is the same as for the genus, with the following additions. Grows at $30^{\circ} \mathrm{C}$, $37^{\circ} \mathrm{C}$ and $42^{\circ} \mathrm{C}$ with $5 \% \mathrm{CO}_{2}$, and in aerobic conditions at $30^{\circ} \mathrm{C}$, and $42^{\circ} \mathrm{C}$. Does not grow in $\mathrm{LB}$ broth or enriched Mycoplasma broth medium. Enzyme tests did not indicate a reaction forindol, trypsin, chymotrypsin, $\alpha$-galactosidase, $\beta$-galactosidase, $\beta$-glucuronidase, $\alpha$ glucosidase, $\beta$-glucosidase, $\mathrm{N}$-acetyl- $\beta$-glucosaminidase, $\alpha$-mannosidase and $\alpha$-fucosidase, urease and prolin arylamidase, alkaline phosphatase, lipase, cystin arylamidase or penicillinase. However, the species exhibits strong enzyme activity of esterase, leucine arylamidase, naphtolAS-BI-phosphohydrolase and $\gamma$-glutamyl transferase, and intermediate activity of esterase lipase, valine arylamidase, acid phosphatase and ornithine decarboxylase. The chemotaxonomic characteristics listed in the type strain genus apply to this strain.

The type strain is B. psittacipulmonis DSM 24701, isolated from the lungs of a parakeet from Basel, Switzerland (= CIP 110308 T, 16S rDNA gene sequence Genbank accession number JX412111 and GI 406042063).

\section{Distribution in the cages and homes of pet owners}

We explored whether this microorganism is common in the environment of pet parakeets by conducting PCRs on environmental templates with PCR primers that are unique to the $B$. psittacipulmonis. Primers were designed to specifically amplify the B. psittacipulmonis $16 \mathrm{~S}$ rDNA gene and several protein-coding genes that were considered unidentified on RAST, and did not yield any hits on BLAST in the nr/nt database. PCR amplification of sample templates from the drinking water and bottom of cages housing healthy parakeets from various pet stores and private homes using these primers were all negative, while positive samples obtained by artificial contamination of the same material with $1 \mathrm{ng}$ of DSM 24701 genomic DNA were positive. This suggests that the DSM 24701 is not commonly found in the cages of healthy parakeets.

\section{Phylogenetic analysis}

Comparative phylogenetic analysis of $16 \mathrm{~S}$ rDNA gene sequence with closely related species reveals that the bacterium is a Betaproteobacterium in the family Alcaligenaceae, closely related to members of the genus Pelistega and the genus Taylorella (Figure 1 contains neighbor joining tree, while Additional file 2: Figure S1 contains maximum likelihood and maximum parsimony trees). A neighbor joining tree of the $r p o B$ gene sequence including $P$. europaea and several related taxa was also constructed (Additional file 3: Figure S2). The RDP naïve Bayesian Classifier assigns DSM 24701 to the family Alcaligenaceae with $100 \%$ confidence, but designates the strain as unclassified Alcaligenaceae with a $60 \%$ bootstrap confidence value for the genus Pelistega. The best match for the $16 \mathrm{~S}$ rDNA gene sequence in the RDP and the NCBI has only 93\% identity (Table 1). Because separation into bacterial genera typically occurs below 95\% 16S rDNA gene sequence identity [21], the new isolate belongs to a new genus within the Alcaligenaceae family [22,23]. Similarly, the most closely related rpoB gene, from $P$. europaea, has only $76 \%$ identity (Additional file 1: Table S2). Separation into bacterial genera typically occurs below $85.5 \%$ rpoB gene identity [24]. The top $16 \mathrm{~S}$ rDNA gene sequence BLAST hits from the all nucleotide $\mathrm{nr} / \mathrm{nt}$ database are also from the Alcaligenaceae family (Table 1), although the top BLAST hits are not actually the closest phylogenetic neighbors [25] as determined with the phylogenetic trees shown in Figure 1 and Additional file 2: Figure S1 and Additional file 3: Figure S2. Phenotypic characteristics, GC content, $16 \mathrm{~S}$ rDNA and $r p o B$ gene identity all place the DSM 24701 close to $P$. europaea and T. equigenitalis (Table 4). The genome comparisons discussed below rely on members of the Alcaligenaceae family whose entire genomes have been sequenced, including two members of the genus Taylorella and several members of the genus Bordetella including $B$. pertussis, the organism that causes whooping cough.

P. europaea has been found in the lungs, trachea, liver and spleen of acutely diseased pigeons; clinical observations have led microbiologists to conclude that it is a pathogenic organism [30]. Low GC content and small genome size, features which are shared by $P$. europaea, Taylorella spp., and this novel bacterium DSM 24701 [31], are different from the closely related, fully sequenced members of the Alcaligenaceae family such as the Bordetella with higher GC content (62-68\%) and genome size (3.7-5.3 Mb) (Table 4).

\section{Genomic analysis}

We used high coverage sequence data $(\sim 350 \times)$ with short reads of 36 bases from Solexa-Illumina, generating 195 contigs, when assembled with Edena (Table 5). A 454 run with only $10 \times$ coverage yielded 977 contigs. Merging this assembly with the one that resulted from the Illumina paired-end data did not improve the contiguity. Moreover, some errors at homopolymers stretches [32] propagated into the merged assembly. Therefore we discarded this data for the rest of the analysis. 


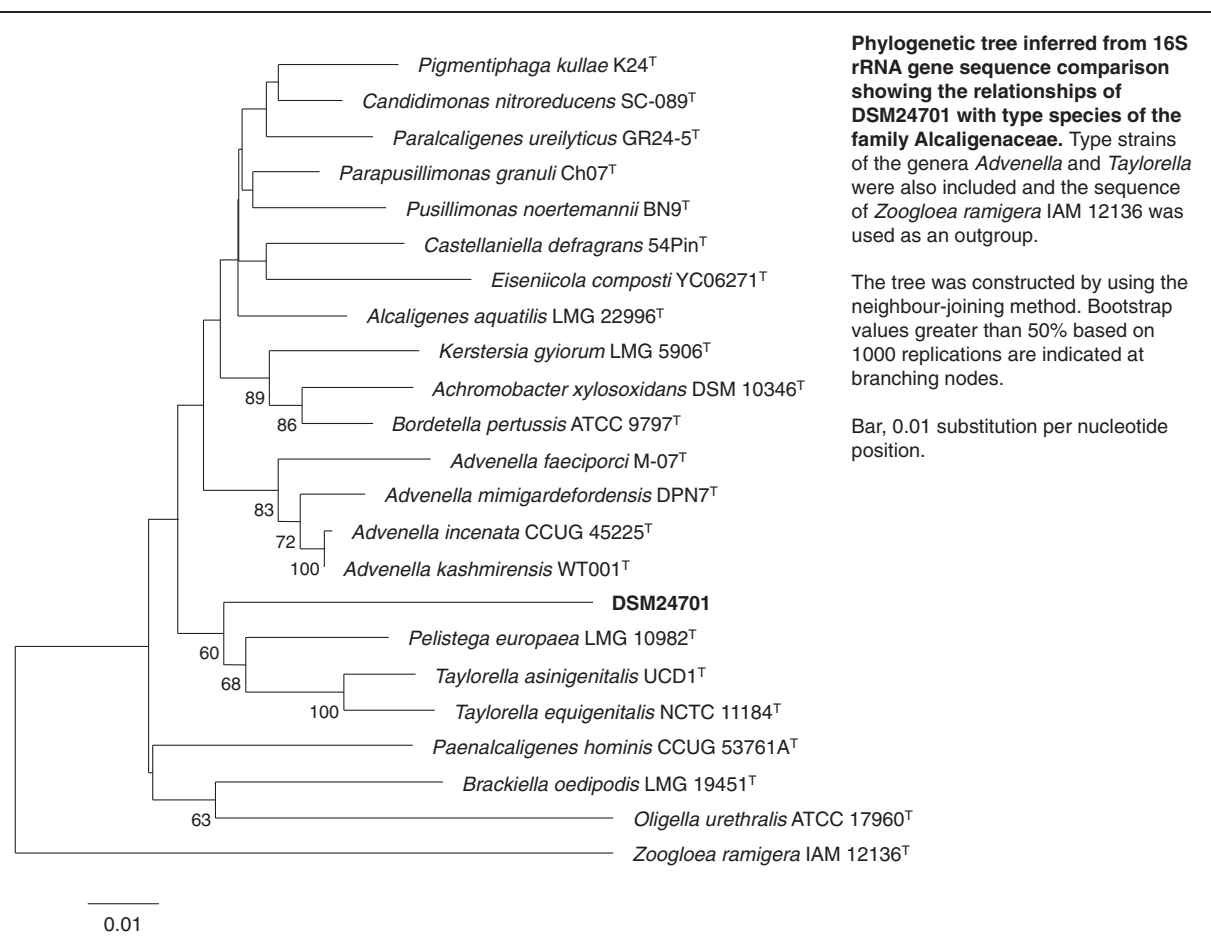

Figure 1 Phylogenetic tree inferred from 16S rDNA gene sequence comparison showing the relationships of DSM 24701 with type species of the family Alcaligenaceae. Type strains of species from the genera Advenella and Taylorella were also included and the sequence of Zoogloea ramigera IAM 12136 was used as an outgroup. The tree was constructed by using the neighbour-joining method. Bootstrap values greater than 50\% based on 1000 replications are indicated at branching nodes. Bar, 0.01 substitution per nucleotide position.

Genome size as determined by contig assembly and optical mapping is near $2 \mathrm{Mb}$ The size of the DSM 24701 genome is estimated to be near $2 \mathrm{Mb}$ by both Solexa-Illumina and 454 sequencing in addition to the results of an optical map generated by electrophoresis of fragments generated by an NheI digest of the genomic
DNA (results not presented). The large effort which would be required to complete the genome was not undertaken. The 195 contigs were submitted for Rapid Annotation using Subsystem Technology [15] (http:// rast.nmpdr.org/). The annotation process found 1664 coding sequences on 88 contigs. The remaining contigs

Table 4 Comparison of DSM 24701 with other betaproteobacteria including many members of the family Alcaligenaceae

\begin{tabular}{|c|c|c|c|c|c|c|}
\hline Strain & Shape & Gram & Genome size (Mb) & Coding sequences & GC \% & Observed growth rate (hours) \\
\hline DSM 24701 & Rod & Neg & 1.9 & $1658^{a}$ & 40 & $\mathrm{n} / \mathrm{a}$ \\
\hline Pelistega europaea & Pleomorphic & Neg & $\mathrm{n} / \mathrm{a}$ & $\mathrm{n} / \mathrm{a}$ & $\sim 43^{\mathrm{d}}$ & $\mathrm{n} / \mathrm{a}$ \\
\hline Taylorella equigenitalis MCE9 & Coccobacillus & Neg & $1.7^{\mathrm{g}}$ & 1557 & $37^{9}$ & $\mathrm{n} / \mathrm{a}$ \\
\hline Taylorella asinigenitalis 14/45 & Coccobacillus & Neg & $1.5^{\mathrm{g}}$ & 1423 & $38^{\mathrm{g}}$ & $\mathrm{n} / \mathrm{a}$ \\
\hline Bordetella avium & Coccobacillus & Neg & $3.7^{b}$ & $3417^{\mathrm{b}} 3463^{\mathrm{a}}$ & $62^{b}$ & $\mathrm{n} / \mathrm{a}$ \\
\hline Bordetella bronchiseptica & Coccobacillus & Neg & $5.3^{b}$ & $5011^{b} 5024^{a}$ & $68^{b}$ & $24-48^{f}$ \\
\hline Bordetella pertussis & Coccobacillus & Neg & $4.1^{b}$ & $3816^{b} 3799^{a}$ & $68^{b}$ & $48-72^{f}$ \\
\hline Bordetella parapertussis & Coccobacillus & Neg & $4.8^{b}$ & $4404^{b} 4452^{a}$ & $68^{b}$ & $48-72^{f}$ \\
\hline Ralstonia solanacearum & Rod & Neg & $5.8^{c}$ & $5129^{c} 5172^{a}$ & $67^{c}$ & $\mathrm{n} / \mathrm{a}$ \\
\hline Acidovorax avenae subsp. citrulli & Rod & Neg & $5.4^{\mathrm{e}}$ & $4709^{e} 4071^{a}$ & $69^{e}$ & $\mathrm{n} / \mathrm{a}$ \\
\hline Burkholderia ambifaria AMMD & Rod & Neg & $7.5^{\mathrm{e}}$ & $6617^{\mathrm{e}} 6275^{\mathrm{a}}$ & $67^{\mathrm{e}}$ & $\mathrm{n} / \mathrm{a}$ \\
\hline Burkholderia cenocepacia & Rod & Neg & $7^{e}$ & $6477^{e} 6142^{a}$ & $67^{\mathrm{e}}$ & $\mathrm{n} / \mathrm{a}$ \\
\hline Advenella kashmirensis & Coccoid & Neg & $4.4^{h}$ & $4563^{h}$ & $54^{h}$ & $48-72^{h}$ \\
\hline
\end{tabular}

${ }^{\mathrm{a}}[15] \rightarrow{ }^{\mathrm{b}}[8] \rightarrow{ }^{\mathrm{c}}[26] \rightarrow^{\mathrm{d}}[27] \rightarrow^{\mathrm{e}}[2] \rightarrow^{\mathrm{f}}[28] \rightarrow{ }^{\mathrm{g}}[9] \rightarrow^{\mathrm{h}}[29]$. 
Table 5 Illumina sequencing data and assembly statistics of the draft genome

\begin{tabular}{ll}
\hline Number of reads & 18596374 \\
Read length & 36 \\
Average pairing distance (standard deviation) & $117.8(10.3)$ \\
Number of contigs & 195 \\
Average contig size & $9.9 \mathrm{Kbp}$ \\
N50 & $41.6 \mathrm{Kbp}$ \\
Max contig size & $99 \mathrm{Kbp}$ \\
Total size* & $1.93 \mathrm{Mb}$ \\
Raw coverage & $347 \times$ \\
RAST predicted coding sequences & 1664 \\
Contigs included in annotation & 88 \\
RNAs & 45 \\
\hline
\end{tabular}

*The genome size was also determined to be $2.2 \mathrm{Mb}$ through Optical Mapping with the restriction enzyme Nhel.

were shorter than the average gene length, suggesting that any gene which may occur on those contigs could be truncated and would be harder for gene-calling algorithms to identify. RAST describes each of the coding sequences as a protein expression gene (peg) numbered 1-1664 as they appear on the contigs which are ordered largest to smallest, i.e. peg. 1 is the first gene on the largest contig.
Common protein coding marker genes and dinucleotide frequency recapitulate relationships found in $16 \mathrm{~S}$ rDNA gene tree The contigs were concatenated into a single molecule and analyzed with ML Tree (http:// mltreemap.org/). This software searches through fully sequenced bacterial genomes for 31 common protein coding marker genes and constructs a phylogenetic tree based on the alignment of the best BLAST matches for these markers [33]. The draft genome of DSM 24701, containing all 31 marker genes on 10 different contigs, was the closest to the genomes of the Bordetella genus (data not shown) [34]. The best blast hits shown in Figure 2 also suggest that predicted genes from Bordetella have the highest sequence similarity with DSM 24701. Interestingly, dinucleotide usage analysis (shown in Additional file 4: Figure S3) recapitulates the phylogenetic relationships found with the $16 \mathrm{~S}$ rDNA gene tree in Figure 1. Dinucleotide usage has a phylogenetic signature that has been shown to reflect the lifestyle and history of a micro-organism [35]. Five CRISPR sequences were identified using Crisprfinder, and two of them had significant blast scores (e value $<1$ e-27) with hypothetical proteins from the genus Neisseria and from Pasteurella multocida (Additional file 1: Table S4). Both Neisseria and Pasteurella can be part of the normal microbiota of humans and animals, while some species of these genera can cause infectious diseases.

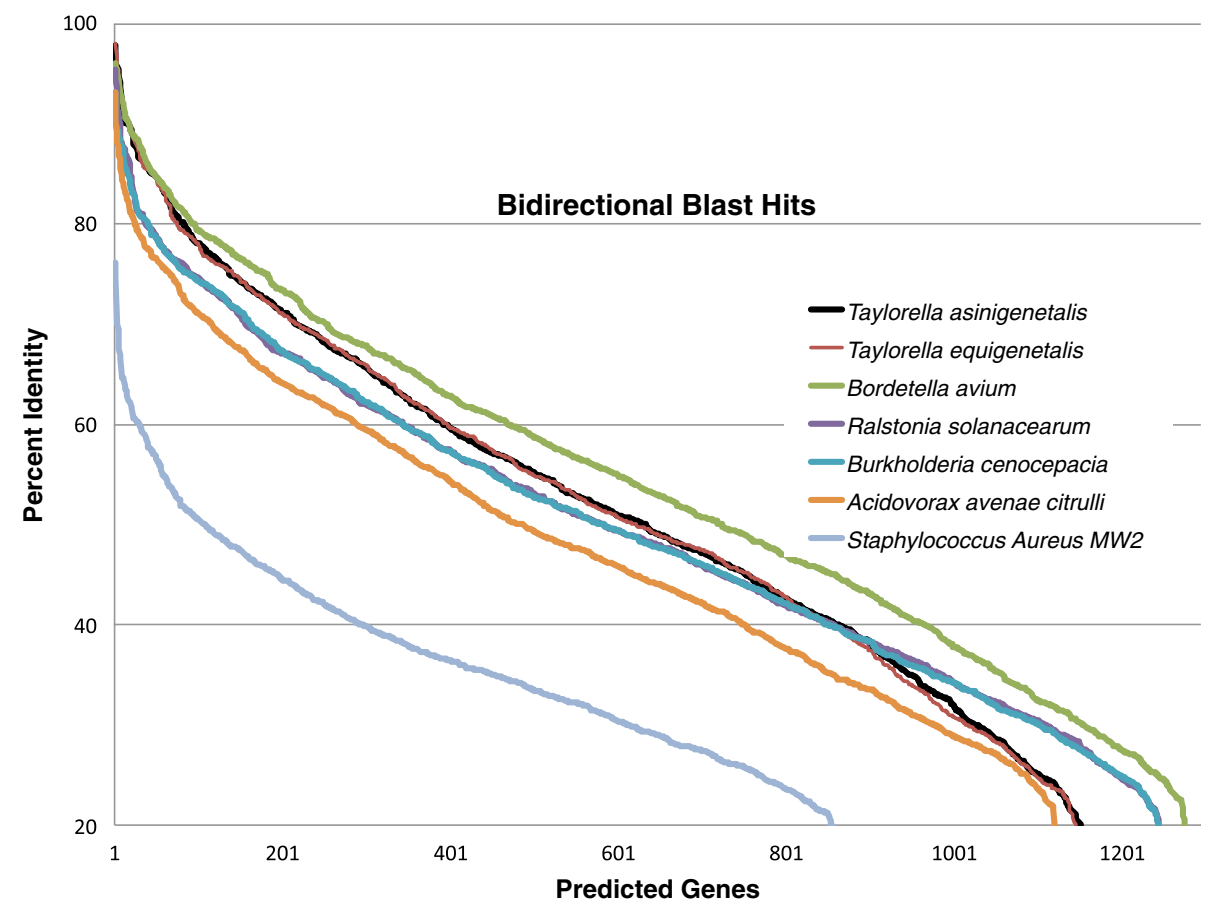

Figure 2 Bidirectional BLASTp hits between predicted genes for DSM 24701 and those of closely related fully sequenced genomes, calculated by RAST as the percent identity of the BLASTp hit (highest-scoring pair of segments). 
Amino acid sequence homology shows that about a third of the predicted genes from DSM 24701 are shared with related genomes Traditionally, bacterial species have been characterized since the 1960s using laborious DNA-DNA hybridization (DDH) with genomic DNA for related organisms, with a cut-off of $50-70 \%$ for members of the same species [36]. Now it is possible to compare the sequences of organisms with fully sequenced genomes, bypassing the need for DDH. Full genome sequence comparison methods such as Average Nucleotide Index (ANI) have been shown to be equivalent to $\mathrm{DDH}$ [36]. Species cutoff values of 70\% DDH have been found to correspond to ANI values of $95 \%$ and $16 \mathrm{~S}$ rDNA gene identity values of $\sim 98 \%[36,37]$. We attempted to make ANI calculations comparing the DSM 24701 sequence with the eight organisms with fully sequenced genomes listed in Figure 2, but found that the ANI calculations were only able to include about $20 \%$ of the genome sequence, and led to ANI values of approximately 65\% [38]. There is not any fully sequenced genome that is similar enough to the DSM 24701 to allow for useful comparison by ANI or DDH. However, comparison of amino acid sequence homology of the predicted genes, as shown in Figure 2 by bidirectional BLAST hits taken from the RAST annotation [15], is a useful way to evaluate the similarities between the DSM 24701 and fully sequenced members of the Alcaligenaceae family. The top most similar genes (Additional file 1: Table S5) include highly conserved proteins, mostly ribosomal proteins. There are only a handful of proteins with $>90 \%$ similarity when comparing this novel species with B. avium, T. equigenitalis and T. asinigenitalis. About a third of the putative genes from DSM 24701 have $>50 \%$ identity with predicted genes from the genomes of Bordetella spp and Taylorella spp (Figure 2). The number of unique genes is quite large: 302 predicted genes have a BLAST identity $<20 \%$ with the B. avium, T. equigenitalis and T. asinigenitalis. Most bacteria have a significant number of unique genes [39]; i.e. T. asinigenitalis has 141 genes absent from T. equigenitalis, and 359 genes not found in B. avium. The spectacular diversity of protein coding sequences in bacterial genomes is a major motivation for large-scale microbial sequencing efforts. Current tools allow us to map out potential functional characteristics of putative genes. However, it can be difficult to make meaningful conclusions about an organism that is not closely related to other sequenced organisms despite obtaining a nearly complete genome sequence. The ring diagram [40] in Figure 3 highlights the sparse homology with the closest sequenced genomes at the amino acid level.

GC Content analysis of concatenated DSM 24701 contigs suggests more recent genetic exchange with organisms that have low GC content Comparison of the GC content of the DSM 24701 with that of B. avium $197 \mathrm{~N}$, T. equigenitalis and T. asinigenitalis over the length of their respective genomes was conducted to look for variation which may indicate horizontal gene transfer (HGT). The DSM 24701 contigs were ordered from largest to smallest and fused into a single contiguous sequence, and the GC content of the four genomes shown in Figure 4 were analyzed in 100 bp windows with the Emboss isochore program [41]. The genome of DSM 24701 has consistently lower GC content than $B$. avium $197 \mathrm{~N}$, and does not appear to have recent HGT events with organisms that have a GC content $>60 \%$, although there are several deviations of significant magnitude into regions of lower GC content. The Taylorella genomes and DSM 24701 have similar GC content. Shared GC content does not indicate greater overall homology; the Taylorella protein coding sequences do not share greater BLAST homology with DSM 24701 than B. avium (Figure 2).

Phylogenetic profiling yields a unique profile of gene clusters, some shared with Bordetella, phage or other respiratory pathogens We conducted a phylogenetic profile by constructing an array with rows consisting of the predicted genes of the DSM 24701 genome, and a column for each completely sequenced bacterium (Figure 5). A BLASTp query of the DSM 24701 predicted genes against a database containing all the genes from fully sequenced genomes in the SEED database was conducted to create a matrix with a 0 or 1 in each position depending on whether there was a BLASTp hit with a cutoff of $1 \mathrm{E}-5$. The clusters of species recapitulate a phylogenetic tree (see Methods). The pattern of gene presence and absence for each species also leads to the formation of functionally related gene clusters. Visualization of this clustered array led to the observation of several interesting regions. For example, a cluster of at least eight putative genes including peg.872-4 involved in Type II/IV secretion are rarely present in any of the sequenced species, including Bordetella, but are consistently found in Yersinia species. A fraction of the genes are also found in other respiratory pathogens including Haemophilus and some potentially opportunistic Shewanella species (Figure 5). The GC content in this cluster is quite similar to that of the DSM 24701 genome, ranging from 36-40\%. Another group of genes encoding bacterial adhesins and autotransporters (including peg.855 and peg.856, described as YadA-like, a well-studied Yersinia spp. protein known to play a role in host-pathogen interaction) is found in several respiratory pathogens, including many Burkholderia species, but does not have a single ortholog in the sequenced genomes of the Bordetella species. These examples illustrate that the DSM 24701 genome can be distinguished from the Bordetella species, and that it shares many genes 


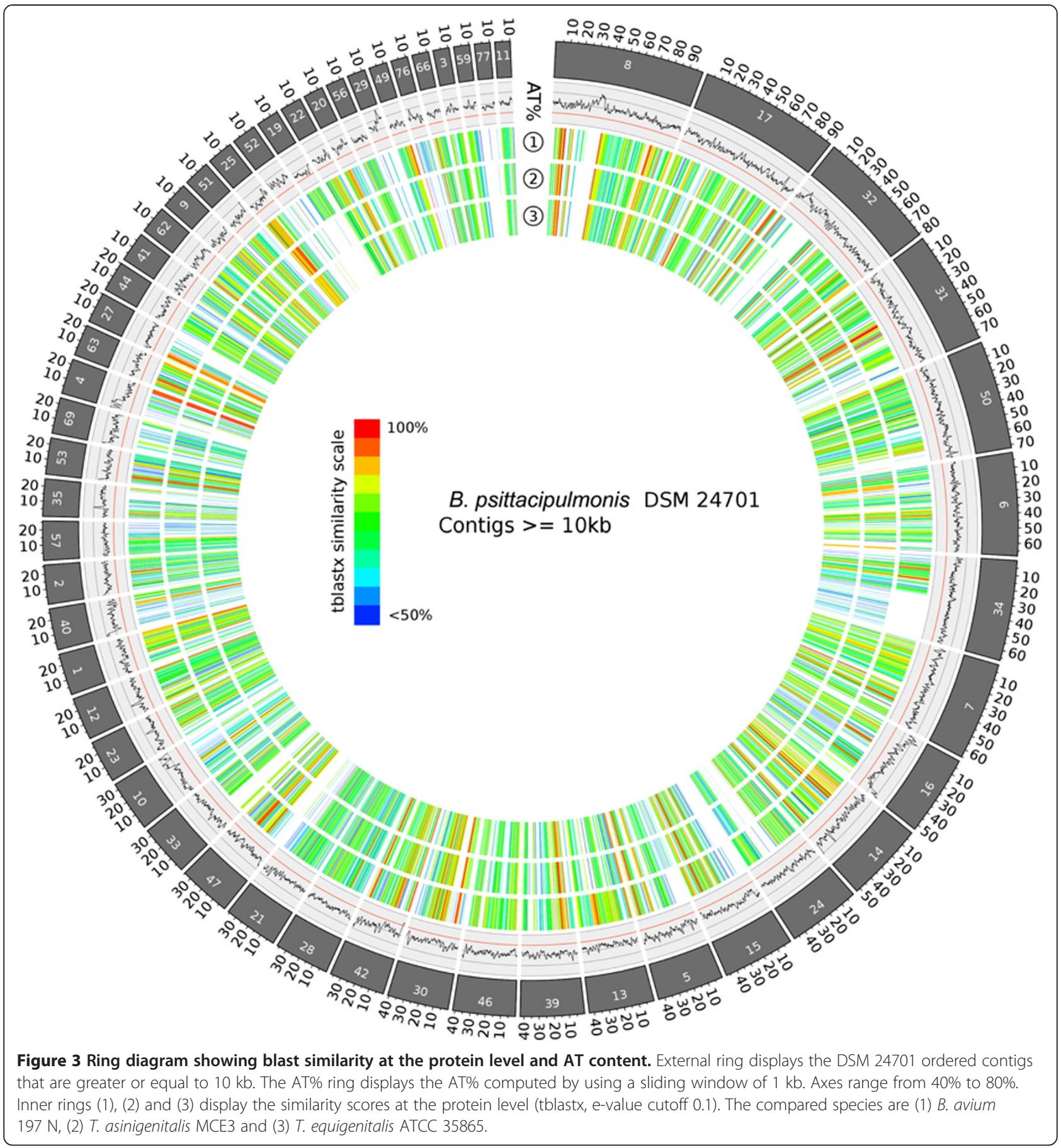

thought to be important for respiratory pathogen species not belonging to the genus Bordetella.

There are also examples of gene clusters formed in the phylogenetic profile that are shared almost exclusively with the Bordetella species. Thirty-four genes in a cluster which is present consistently only in the Bordetella species are mostly described as hypothetical, but include genes predicted to be integral membrane proteins, TolA and a RecB-family exonuclease. Another intriguing cluster of 11 predicted genes that are all present in both genome sequences of $B$. avium encodes putative phage proteins, including the small terminase subunit involved in DNA packaging. Ten of the eleven genes in this cluster are located together on a contig of the DSM 24701 genome with the same gene order as the Bordetella species. We were surprised to find that the GC content of the DSM 24701 genes in this cluster ranged from 42-48\%, while the orthologs from Bordetella species and several 


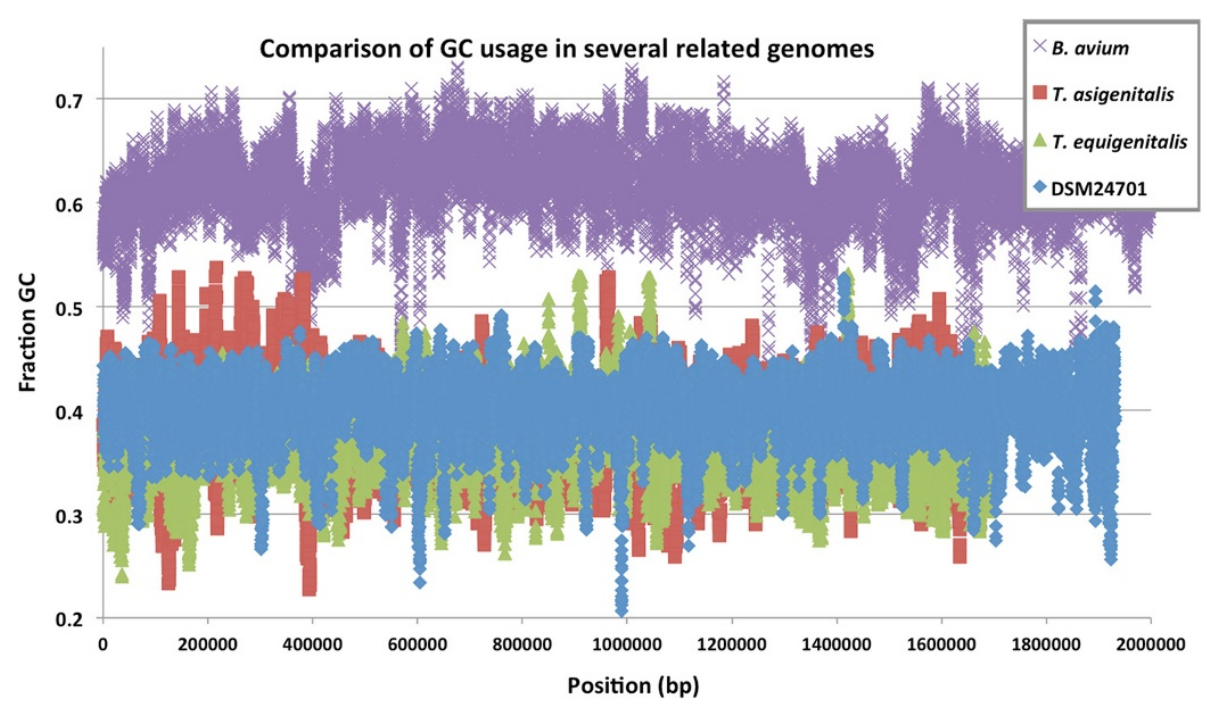

Figure 4 Comparison of the GC content of the DSM 24701, B. avium $197 \mathrm{~N}, T$. equigenitalis and T. asinigenitalis.

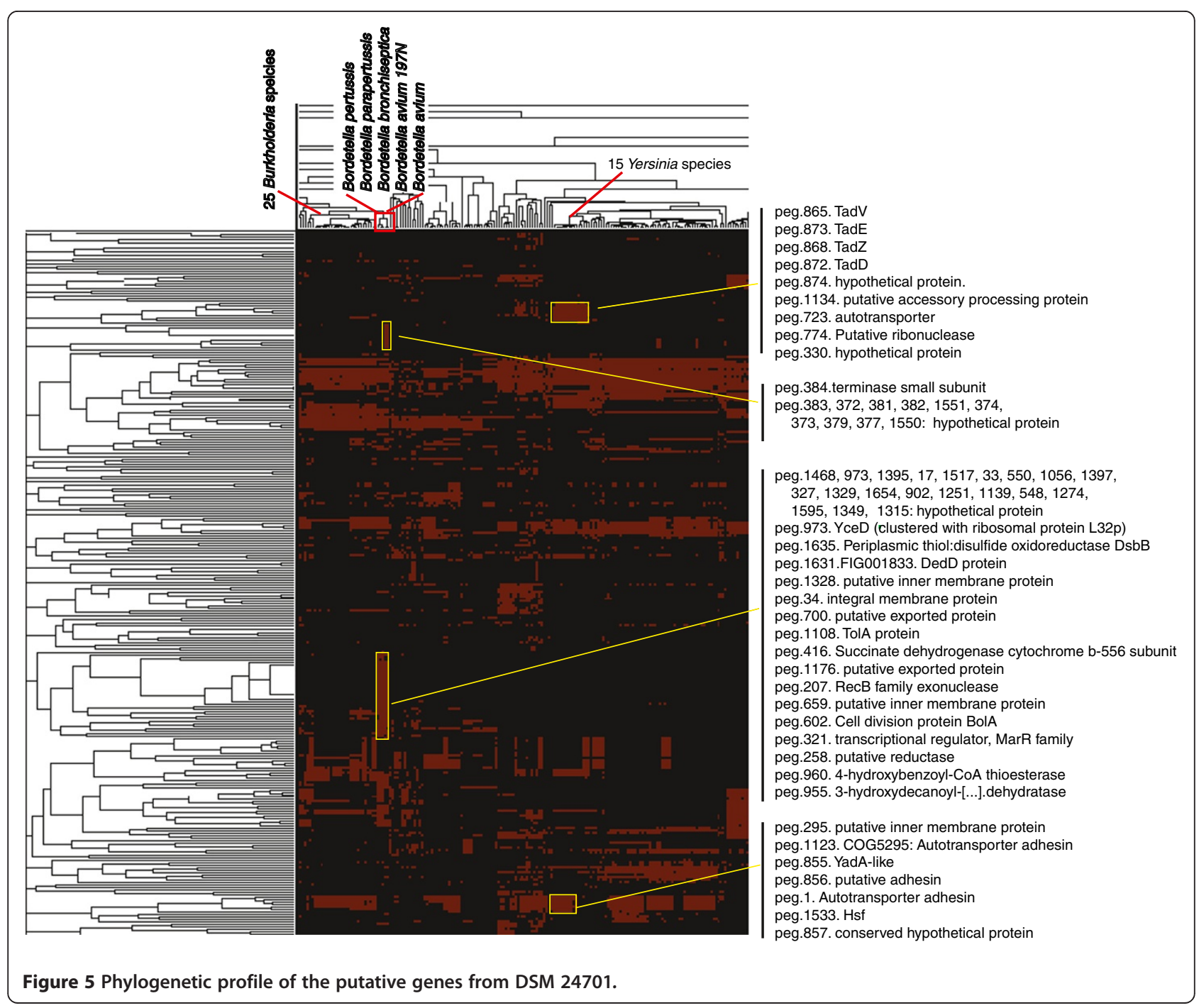


sequenced Bordetella phages have GC contents similar to that of their genomes just under $70 \%$. The predicted phage terminase from DSM 24701 has 48\% GC, which is high compared to the rest of the genome (Figure 4). It is interesting that this putative prophage cassette has such different GC content in DSM 24701 and Bordetella species; the difference may derive from a different phage or quick adaptation of the cassette sequence to a lower GC content in DSM 24701.

DSM 24701 shares some gene loss events with obligate intracellular bacteria Of the 100 COGs lost by all obligate intracellular bacteria in a study of 317 genomes [12], only $\sim 30$ of them had equivalent representatives in the genome of strain DSM 24701 using the RAST annotation of predicted gene function. Strain DSM 24701 is not dependent on host cells; it is able to grow on blood agar plates. However, small genome size, high GC content and lack of $\sim 70$ genes also missing in obligate intracellular bacteria may indicate that DSM 24701 has taken steps on the one-way road toward gene loss like that which led other bacteria to become host dependent. Merkej et al [12] found that free living bacteria with larger genomes often have more genes that are described as virulence factors than pathogenic bacteria, challenging many early hypotheses that the presence of particular virulence factors was predictive of the pathogenicity of an organism [12]. In addition, HGT is more difficult for intracellular bacteria, which are isolated from encounters with genetically diverse microorganisms and phage.
Mutations that affect gene regulation may also drive virulence in bacteria that can otherwise inhabit humans as harmless commensals, such as Streptococcus pyogenes $[42,43]$, a bacterial species with similar genome size. Future annotation methods may become better at capturing these aspects of pathogenicity and bacterial lifestyle from genomic data.

Distribution of gene function annotation is similar to Taylorella genomes, and reflects the diverse repertoire of metabolic genes in DSM 24701 Figure 6 shows the functional categories that RAST was able to assign to 1041 out of the 1664 predicted DSM 24701 genes, in comparison with the functional categories RAST assigned to $B$. avium, T.equigenitalis and T. asinigenitalis. The distribution for many categories is similar, especially for the closely related Taylorella genomes. There are some differences in the percentage of genes assigned to several metabolic categories - DSM 24701 is enriched for genes involved in protein, amino acid and nitrogen metabolism, along with carbohydrate and fatty acid metabolism and respiration, which suggest that DSM 24701 has maintained a diverse repertoire of metabolic genes. This may reflect the relative independence of DSM 24701 from the host, or a niche that requires broad metabolic capabilities.

DSM 24701 shares low duplication rate with bacteria of similar genome size The presence of gene paralogs derived from duplication or HGT in bacteria is known to correspond to genome size and lifestyle. A comparison of

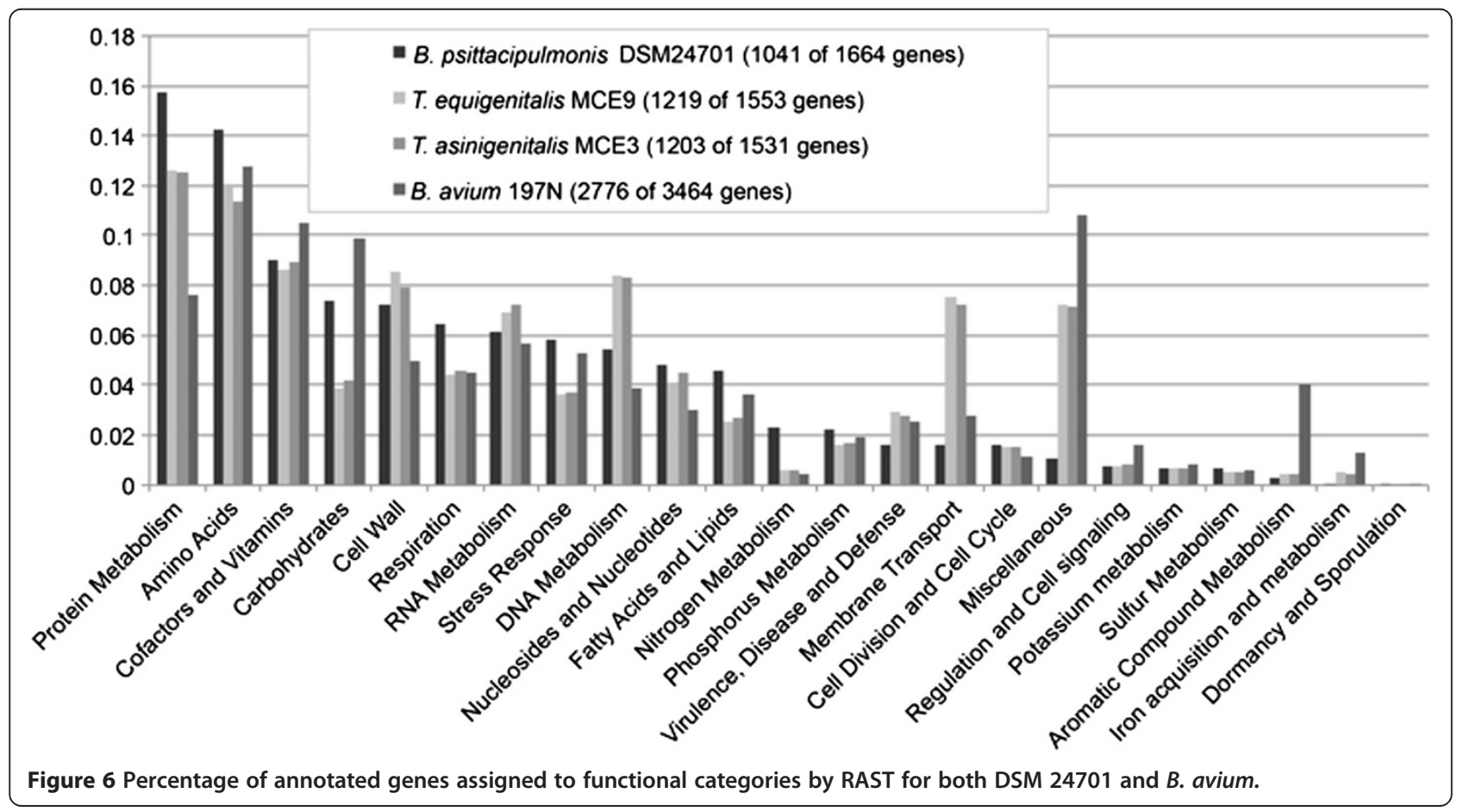


duplication rates in 106 completely sequenced genomes in 2005 found that the paralogs represented, on average, 23.5 $\pm 8.7 \%$ of the predicted genes, ranging from $7 \%$ for Rickettsia conorii Malish 7 to $41 \%$ for Streptomyces coelicolor A3 (2) [20]. Using similar standards (see Methods) we found a duplication rate of 13\% in DSM 24701. Low rates of duplication are associated with smaller genome size and host dependence. Table 6 shows the distribution of paralogs. Both peg.144 and peg.218 have seven paralogs in the genome, and they are both predicted to be $\mathrm{ABC}$ transporters, which are infamous for having large duplication rates.

Shared gene homology varies widely inside bacterial families Several recent genome comparison studies have drawn intriguing conclusions about genome evolution and organization. For example, the Mycoplasma agalactiae genome, long assumed to have undergone genome reduction in order to become one of the simplest freeliving organisms with a minimal genome, was unexpectedly found to have a large fraction of predicted genes $18 \%$ - likely acquired by HGT from species in distinct phylogenetic groups [31]. Sequencing of 16 Mycoplasma genomes allowed for detailed comparison between closely related species, revealing that the genomes are not very similar. For example, in a comparison of $M$. agalactiae strain PG2 with four other Mycoplasma genomes, no predicted genes with a blastp identity $>90 \%$ were found, and only few $(16 \%)$ with $>50 \%$. The genome of DSM 24701 is actually more similar to Bordetella species than this - about a third of the DSM 24701 genome has $>50 \%$ identity with the sequenced Taylorella and Bordetella genomes (Figure 2).

In an attempt to better understand the biology of the newly discovered DSM 24701, and to intimate whether it is a pathogen, we also examined the putative genes that are unique to DSM 24701 in comparison to B. avium, T. equigenitalis and T. asinigenitalis (Additional file 1: Table S6). The unique genes include potential antibiotic resistance genes, CRISPR-related proteins, and members of the Tad (tight adherence gene) macromolecular

Table 6 Distribution of gene paralogs within the DSM 24701genome

\begin{tabular}{ll}
\hline Singlets & 1451 \\
Pairs & 135 \\
Genes in 2 pairs & 58 \\
Genes in 3 pairs & 13 \\
Genes in 4 pairs & 4 \\
Genes in 7 pairs & 2 \\
Genes with paralogs (all pairs) & $213(13.3 \%)$ \\
Total genes (>150 bp) & 1606 \\
Excluded genes (<150 bp) & 57 \\
\hline
\end{tabular}

transport system that may indicate that the secretion systems used by DSM 24701 are different (Additional file 5: Figure S4). This ancient secretion system is found in a long list of pathogenic genera, such as species belonging to the genera of Haemophilus and Yersinia. The tad genes found in many bacteria, including DSM 24701, are known to be involved in biofilm formation and colonization [44], which are essential in the first steps of infection by many bacterial pathogens.

\section{Conclusions}

The organism described in our study (internal strain nr. JF4266, and referred to in this paper as DSM 24701) is different from the other genera belonging to the family Alcaligenaceae, according to phylogenetic, phenotypic and chemotaxonomic data. A new bacterial genus and species are proposed in order to place it taxonomically, with the name Basilea psittacipulmonis gen. nov., sp. nov. (originating from Basel, Switzerland and found in the lungs of Psittacidae). The presence of this easily cultured and yet unassigned bacterial strain, isolated from a common parakeet in a Basel petshop suggests that there may still be large parts of the bacterial kingdom which remain underexplored, even in the midst of the metagenomic revolution that has already yielded many Proteobacteria genome sequences.

The genomic sequence of a newly detected bacterium DSM 24701 will contribute to available sequence knowledge, with many genes that are not similar to any found in current databases. Sequence homology with related genomes, biochemical comparisons, dinucleotide usage, Crispr-detection and phylogenetic profiling allowed us to highlight several interesting features of this genome. However, as the passing of the 10 year anniversary of the human genome and our still vague understanding of its contents remind us, sequence information provides only limited biological knowledge of a live species. Additional sequence information from more closely related organisms would enable improved phylogenetic placement and, to some extent, functional characterization. Sequencing novel organisms even an under-represented branch of a well-studied phyla adds more unique information to the sequence databases, as recently shown by Jonathan Eisen and colleagues from the Genomic Encyclopedia of Bacteria and Archaea (GEBA) [3]. Although it is more difficult to analyze novel genomic sequence in comparative studies, the novel sequences may become starting material for unforeseen biotechnology projects or discoveries in microbial evolution.

\section{Data access}

The assembled and annotated genome is publically on the RAST server with a guest account under the ID 666666.4954, and the $16 \mathrm{~S}$ sequence has the Genbank accession number JX412111 and GI 406042063. 16S rDNA 
and $r p o B$ gene alignments for phylogenetic tree construction can be found in the Dryad database: http://doi. org/10.5061/dryad.b341k.

\section{Additional files}

\section{Additional file 1: Table S1. Growth comparison of Basilea}

psittacipulmonis DSM 24701 and several closely related species in the conditions described. Table S2. BLASTn hits to the DSM24701 rpoB gene sequence for several related taxa also shown in the neighbor joining tree in Additional file 3: Figure S2. Table S3. Cellular fatty acid composition of DSM 24701. Table S4. Crisprs found in DSM24701. Table S5. Bidirectional BLASTp hits for all genes with greater than 90\% identity between DSM 24701 and three of the closest fully sequenced genomes, B. avium, Taylorella equigenitalis and T. asigenitalis. Table S6. A subset of the 302 predicted proteins from RAST annotation that are unique to DSM 24701 in a blast comparison of DSM 24701, B. avium, T. equigenetalis and T. asigenitalis. 179 of the 302 unique genes were annotated as hypothetical proteins, without a predicted function

Additional file 2: Figure S1. Phylogenetic trees based on maximumlikelihood (A) and maximum-parsimony (B) analyses of the rRNA gene sequences showing the relationships of DSM 24701 with type species of the family Alcaligenaceae. Type strains of the genera Advenella and Taylorella were also included and the sequence of Zoogloea ramigera IAM 12136 was used as an outgroup. Bootstrap values greater than 50\% based on 1000 replications are indicated at branching nodes. Bar, 0.01 substitution per nucleotide position.

Additional file 3: Figure S2. Phylogenetic tree inferred from rpo $B$ gene sequence comparison showing the relationships of DSM24701 with selected members of the family Alcaligenaceae. All type species of the genera within the family Alcaligenaceae, for which the rpoB sequences were available, were included. For the genera Advenella and Pusillimonas, non-type species were included. The genus Taylorella was represented by the type species ( $T$. equigenitalis) and a non-type species ( $T$. asinigenitalis). Whenever possible, the type strains of the species were used. The sequence of Dechloromonas aromatica RCB was used as an outgroup. The tree was constructed by using the neighbour-joining method. Bootstrap values greater than $50 \%$ based on 1000 replications are indicated at branching nodes. Bar, $0.05 \mathrm{~s}$

Additional file 4: Figure S3. Dinucleotide usage profile of DSM 2470 and several closely related fully sequenced bacteria. Multi-Dimensional scaling of a Bray-Curtis distance matrix of dinucleotide abundance tables is shown.

Additional file 5: Figure S4. The tad locus on contig 35 of the DSM 24701. Numbered genes code for: 1. TadA, 2. RcpA, 3. TadB, 4. TadC, 5. TadZ, 6. TadD, 7. TadV, 8. Hypothetical protein, 9. Putative membrane protein, 10. RcpC, 11 Putative membrane protein, 12. TolR.

\section{Competing interests}

The authors declare that they have no competing interests.

\section{Authors' contributions}

$\mathrm{KW}$ analyzed the genome and wrote the manuscript, DH performed sequence analysis including assembly of sequence reads, LF performed the Illumina sequencing, JF and PP encountered the bacterium, performed phenotypic analyses and provided the original strain along with contributing ideas and discussion, NG constructed phylogenetic trees based on 165 rDNA gene sequences, $\mathrm{VL}$ conceived and performed the environmental sample PCRs on parakeet cage and water samples along with contributing extensive ideas and manuscript edits, and PF and JS supervised the project, contributing ideas and enthusiasm. All authors read and approved the final manuscript.

\section{Acknowledgements}

We greatly appreciate the contribution of Myriam Girard, who cultured this bacterium and extracted genomic DNA multiple times, enabling these experiments. We would like to acknowledge Manuel Stark and Christian von
Mering, Zürich, for running ML Tree before the standalone program was available. Michael Richter and Ramon Rosello-Mora from Esporles, Spain ran J species in a generous attempt to make an ANI calculation. Manon and Loane Croset, $\mathrm{H}$. Dussolier, along with Maud and Alix François made critical contributions in the collection of parakeet cage and water samples. Jonathan Eisen made several helpful suggestions, especially with regard to phylogenetic profiling. COST (C05.0103) provided funding for common projects to Jacques Schrenzel and Joachim Frey. Katrine Whiteson was supported by an NIH Fellowship (R01GM095384 - 01S1). Finally, we would like to thank a certain parakeet who encountered this bacterium, enabling our study.

\section{Author details}

${ }^{1}$ Genomic Research Laboratory, Department of Internal Medicine, Service of Infectious Diseases, Geneva University Hospitals, Gabrielle-Perret-Gentil 4, CH-1211 Geneva 14, Switzerland. 'Fasteris SA, CH-1228 Plan-les-Ouates, Switzerland. ${ }^{3}$ Institute of Veterinary Bacteriology, University of Bern, Länggassstrasse 122, Postfach, CH-3001 Bern, Switzerland. ${ }^{4}$ Clinical Microbiology Laboratory, Department of Internal Medicine, Service of Infectious Diseases, Geneva University Hospitals, Gabrielle-Perret-Gentil 4, $\mathrm{CH}-1211$ Geneva14, Switzerland. ${ }^{5}$ Current address: Department of Biology, San Diego State University, San Diego, CA, USA.

Received: 4 October 2013 Accepted: 6 February 2014 Published: 1 March 2014

\section{References}

1. Lepore J: It's spreading: outbreaks, media scares, and the parrot panic of 1930. The New Yorker 2009, 46

2. Genome List - National Center for Biotechnology Information. [http://www. ncbi.nlm.nih.gov/genome/browse/]

3. Wu D, Hugenholtz P, Mavromatis K, Pukall R, Dalin E, Ivanova NN, Kunin V, Goodwin L, Wu M, Tindall BJ, Hooper SD, Pati A, Lykidis A, Spring S, Anderson IJ, D'haeseleer P, Zemla A, Singer M, Lapidus A, Nolan M, Copeland A, Han C, Chen F, Cheng J-F, Lucas S, Kerfeld C, Lang E, Gronow S, Chain P, Bruce D et al. A phylogeny-driven genomic encyclopaedia of bacteria and archaea. Nature 2009, 462(7276):1056-1060.

4. A Genomic Encyclopedia of Bacteria and Archaea (GEBA). [http://www.jgi.doe. gov/programs/GEBA/]

5. Wang Q, Garrity GM, Tiedje JM, Cole JR: Naive Bayesian classifier for rapid assignment of rRNA sequences into the new bacterial taxonomy. Appl Environ Microbiol 2007, 73(16):5261-5267.

6. Cole JR, Wang Q, Cardenas E, Fish J, Chai B, Farris RJ, Kulam-Syed-Mohideen AS, McGarrell DM, Marsh T, Garrity GM, Tiedje JM: The ribosomal database project: improved alignments and new tools for rRNA analysis. Nucleic Acids Res 2009, 37(Database issue):D141-D145.

7. Tringe SG, Hugenholtz P: A renaissance for the pioneering $16 \mathrm{~S}$ rRNA gene. Curr Opin Microbiol 2008, 11(5):442-446.

8. Sebaihia M, Preston A, Maskell DJ, Kuzmiak H, Connell TD, King ND, Orndorff PE, Miyamoto DM, Thomson NR, Harris D, Goble A, Lord A, Murphy L, Quail MA, Rutter S, Squares R, Squares S, Woodward J, Parkhill J, Temple LM: Comparison of the genome sequence of the poultry pathogen Bordetella avium with those of B. bronchiseptica, B. pertussis, and B. parapertussis reveals extensive diversity in surface structures associated with host interaction. J Bacteriol 2006, 188(16):6002-6015.

9. Hauser H, Richter DC, van Tonder A, Clark L, Preston A: Comparative genomic analyses of the Taylorellae. Vet Microbiol 2012, 159(1-2):195-203.

10. Hébert L, Moumen B, Duquesne F, Breuil M-F, Laugier C, Batto J-M, Renault P, Petry S: Genome sequence of Taylorella equigenitalis MCE9, the causative agent of contagious equine metritis. I Bacterio/ 2011, 193(7):1785

11. Hébert L, Moumen B, Pons N, Duquesne F, Breuil M-F, Goux D, Batto J-M, Laugier C, Renault P, Petry S: Genomic characterization of the Taylorella genus. PLOS ONE 2012, 7(1):e29953.

12. Merhej $V$, Royer-Carenzi M, Pontarotti P, Raoult D: Massive comparative genomic analysis reveals convergent evolution of specialized bacteria. Biol Direct 2009, 4:13.

13. Faveri M, Mayer MP, Feres M, de Figueiredo LC, Dewhirst FE, Paster BJ: Microbiological diversity of generalized aggressive periodontitis 
by $16 \mathrm{~S}$ rRNA clonal analysis. Oral Microbiol Immunol 2008, 23(2):112-118

14. Hernandez D, Francois P, Farinelli L, Osteras M, Schrenzel J: De novo bacterial genome sequencing: millions of very short reads assembled on a desktop computer. Genome Res 2008, 18(5):802-809.

15. Aziz RK, Bartels D, Best AA, DeJongh M, Disz T, Edwards RA, Formsma K, Gerdes S, Glass EM, Kubal M, Meyer F, Olsen GJ, Olson R, Osterman AL, Overbeek RA, McNeil LK, Paarmann D, Paczian T, Parrello B, Pusch GD, Reich C, Stevens R, Vassieva O, Vonstein V, Wilke A, Zagnitko O: The RAST server: rapid annotations using subsystems technology. BMC Genomics 2008, 9:75.

16. Tamura K, Peterson D, Peterson N, Stecher G, Nei M, Kumar S: MEGA5: molecular evolutionary genetics analysis using maximum likelihood, evolutionary distance, and maximum parsimony methods. Mol Biol Evol 2011, 28(10):2731-2739.

17. Clarke KR: Non-parametric multivariate analyses of changes in community structure. Aust J Ecol 1993, 18(1):117-143.

18. Grissa I, Vergnaud G, Pourcel C: CRISPRFinder: a web tool to identify clustered regularly interspaced short palindromic repeats. Nucleic Acids Res 2007, 35(Web Server issue):W52-W57.

19. Wu M, Ren Q, Durkin AS, Daugherty SC, Brinkac LM, Dodson RJ, Madupu R, Sullivan SA, Kolonay JF, Haft DH, Nelson WC, Tallon LJ, Jones KM, Ulrich LE, Gonzalez JM, Zhulin IB, Robb FT, Eisen JA: Life in hot carbon monoxide: the complete genome sequence of Carboxydothermus hydrogenoformans Z-2901. PLoS Genet 2005, 1(5):e65.

20. Gevers D, Vandepoele K, Simillon C, Van de Peer Y: Gene duplication and biased functional retention of paralogs in bacterial genomes. Trends Microbiol 2004, 12(4):148-154.

21. Schloss PD, Handelsman J: Introducing DOTUR, a computer program for defining operational taxonomic units and estimating species richness. Appl Environ Microbiol 2005, 71(3):1501-1506.

22. Vandamme P, Pot B, Gillis M, de Vos P, Kersters K, Swings J: Polyphasic taxonomy, a consensus approach to bacterial systematics. Microbiol Rev 1996, 60(2):407-438.

23. Gevers D, Cohan FM, Lawrence JG, Spratt BG, Coenye T, Feil EJ, Stackebrandt E, Van de Peer Y, Vandamme P, Thompson FL, Swings J: Opinion: re-evaluating prokaryotic species. Nat Rev Microbiol 2005, 3(9):733-739.

24. Adékambi T, Shinnick TM, Raoult D, Drancourt M: Complete rpoB gene sequencing as a suitable supplement to DNA-DNA hybridization for bacterial species and genus delineation. Int J Syst Evol Microbiol 2008, 58(8):1807-1814

25. Koski LB, Golding GB: The closest BLAST hit is often not the nearest neighbor. J Mol Evol 2001, 52(6):540-542.

26. Salanoubat M, Genin S, Artiguenave F, Gouzy J, Mangenot S, Arlat M, Billault A, Brottier P, Camus JC, Cattolico L, Chandler M, Choisne N, Claudel-Renard C, Cunnac S, Demange N, Gaspin C, Lavie M, Moisan A, Robert C, Saurin W, Schiex T, Siguier $P$, Thébault $P$, Whalen $M$, Wincker $P$, Levy M, Weissenbach J, Boucher CA: Genome sequence of the plant pathogen Ralstonia solanacearum. Nature 2002, 415(6871):497-502.

27. Boone DR, Castenholz RW, Garrity GM: Bergey's manual of systematic bacteriology. 2nd edition. New York: Springer; 2001

28. Goodnow RA: Biology of Bordetella bronchiseptica. Microbiol Rev 1980, 44(4):722-738

29. Ghosh W, George A, Agarwal A, Raj P, Alam M, Pyne P, Gupta SKD: Wholegenome shotgun sequencing of the sulfur-oxidizing chemoautotroph tetrathiobacter kashmirensis. J Bacteriol 2011, 193(19):5553-5554.

30. Dworkin M, Falkow S: The prokaryotes : a handbook on the biology of bacteria. 3rd edition. New York; London: Springer; 2006.

31. Sirand-Pugnet $P$, Lartigue $C$, Marenda M, Jacob D, Barre A, Barbe V, Schenowitz C, Mangenot S, Couloux A, Segurens B, de Daruvar A, Blanchard A, Citti C: Being pathogenic, plastic, and sexual while living with a nearly minimal bacterial genome. PLoS Genet 2007, 3(5):e75.

32. Margulies M, Egholm M, Altman WE, Attiya S, Bader JS, Bemben LA, Berka J, Braverman MS, Chen Y-J, Chen Z, Dewell SB, Du L, Fierro JM, Gomes XV, Godwin BC, He W, Helgesen S, Ho CH, Irzyk GP, Jando SC, Alenquer MLI, Jarvie TP, Jirage KB, Kim J-B, Knight JR, Lanza JR, Leamon $J H$, Lefkowitz SM, Lei $M$, Li J et al: Genome sequencing in microfabricated high-density picolitre reactors. Nature 2005, 437(7057):376-380.

33. von Mering C, Hugenholtz P, Raes J, Tringe SG, Doerks T, Jensen LJ, Ward N, Bork P: Quantitative phylogenetic assessment of microbial communities in diverse environments. Science 2007, 315(5815):1126-1130.
34. Stark M, Berger SA, Stamatakis A, von Mering C: MLTreeMap - accurate Maximum Likelihood placement of environmental DNA sequences into taxonomic and functional reference phylogenies. BMC Genomics 2010, 11:461.

35. Willner D, Thurber RV, Rohwer F: Metagenomic signatures of 86 microbial and viral metagenomes. Environ Microbiol 2009, 11(7):1752-1766.

36. Goris J, Konstantinidis KT, Klappenbach JA, Coenye T, Vandamme P, Tiedje JM: DNA-DNA hybridization values and their relationship to whole-genome sequence similarities. Int J Syst Evol Microbiol 2007, 57(Pt 1):81-91.

37. Konstantinidis KT, Ramette A, Tiedje JM: Toward a more robust assessment of intraspecies diversity, using fewer genetic markers. App/ Environ Microbiol 2006, 72(11):7286-7293.

38. Richter M, Rosselló-Móra R: Shifting the genomic gold standard for the prokaryotic species definition. Proc Natl Acad Sci USA 2009, 106:19126-19131.

39. Kuo $\mathrm{CH}$, Ochman $\mathrm{H}$ : The fate of new bacterial genes. FEMS Microbiol Rev 2009, 33(1):38-43.

40. Krzywinski M, Schein J, Birol I, Connors J, Gascoyne R, Horsman D, Jones SJ, Marra MA: Circos: an information aesthetic for comparative genomics. Genome Res 2009, 19(9):1639-1645.

41. Rice $P$, Longden I, Bleasby A: EMBOSS: the European molecular biology open software suite. Trends Genet 2000, 16(6):276-277.

42. Aziz RK, Nizet V: Pathogen microevolution in high resolution. Sci Trans/ Med 2010, 2(16):16ps14.

43. Walker MJ, Hollands A, Sanderson-Smith ML, Cole JN, Kirk JK, Henningham A, McArthur JD, Dinkla K, Aziz RK, Kansal RG, Simpson AJ, Buchanan JT, Chhatwal GS, Kotb M, Nizet V: DNase Sda1 provides selection pressure for a switch to invasive group A streptococcal infection. Nat Med 2007, 13(8):981-985.

44. Tomich M, Planet PJ, Figurski DH: The tad locus: postcards from the widespread colonization island. Nat Rev Microbiol 2007, 5(5):363-375.

doi:10.1186/1471-2164-15-169

Cite this article as: Whiteson et al.: A genomic perspective on a new bacterial genus and species from the Alcaligenaceae family, Basilea psittacipulmonis. BMC Genomics 2014 15:169.

\section{Submit your next manuscript to BioMed Central and take full advantage of:}

- Convenient online submission

- Thorough peer review

- No space constraints or color figure charges

- Immediate publication on acceptance

- Inclusion in PubMed, CAS, Scopus and Google Scholar

- Research which is freely available for redistribution

Submit your manuscript at www.biomedcentral.com/submit
C) Biomed Central 